\title{
Density Functional Theory Studies of Doping and Curvature Effects on the Electrocatalytic Hydrogen Evolution Activity of Carbon
}

\section{Nanotubes}

\author{
Qian Xu, Hui Li*, Yu Shi, Zhonglin Bi, Yang Wu* \\ College of Chemistry, Liaoning University, 66 Chongshan Middle Road, Shenyang, \\ Liaoning, 110036, People's Republic of China \\ E-mail: wuyang@lnu.edu.cn ; lihui@,lnu.edu.cn \\ *Author to whom correspondence should be addressed:
}

\section{Supplementary Materials}

\begin{tabular}{|c|c|}
\hline FORMATION ENERGY & $\mathbf{S - 2}$ \\
\hline FLUCTUATIONS OF TOTAL ENERGY & $\mathbf{S - 2}$ \\
\hline PDOS FOR CNTS & $\mathbf{S - 3}$ \\
\hline$\Delta G_{\mathrm{H}^{*}}$ OF N $_{\text {site }^{-}}$1N-CNTS & $\mathbf{S - 3}$ \\
\hline
\end{tabular}




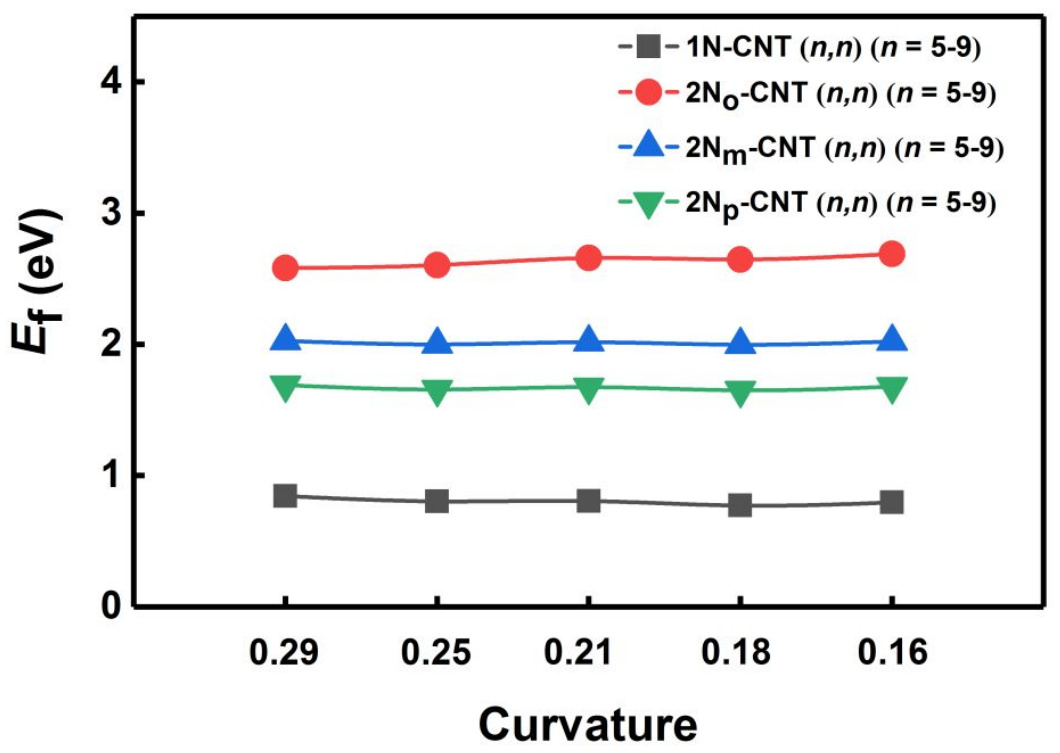

Figure S1. Formation energy $\left(\mathrm{E}_{\mathrm{f}}\right)$ for $\mathrm{CNT}(n, n)(n=5-9)$ and $m \mathrm{~N}_{\mathrm{y}}-\mathrm{CNT}(n, n)(m=1$, 2 and $\mathrm{y}=\mathrm{o}, \mathrm{m}, \mathrm{p}$ and $n=5-9)$

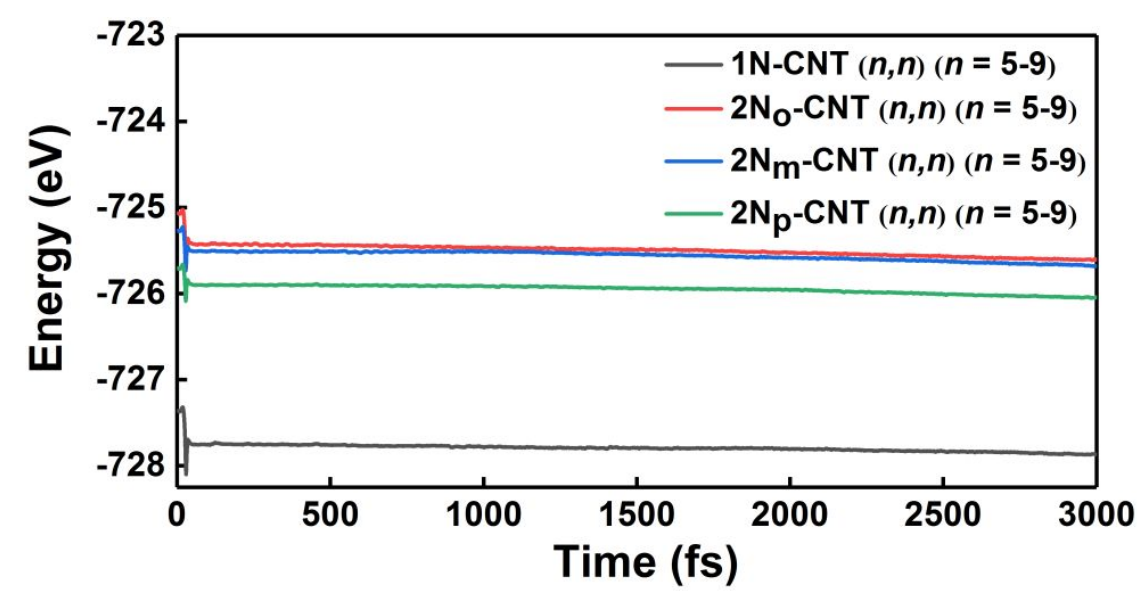

Figure S2. The fluctuations of total energy of CNT $(n, n)(n=5-9)$ and $m \mathrm{~N}_{\mathrm{y}}-\mathrm{CNT}$ $(n, n)(m=1,2$ and $\mathrm{y}=\mathrm{o}, \mathrm{m}, \mathrm{p}$ and $n=5-9)$ during the AIMD simulations at $300 \mathrm{~K}$. 


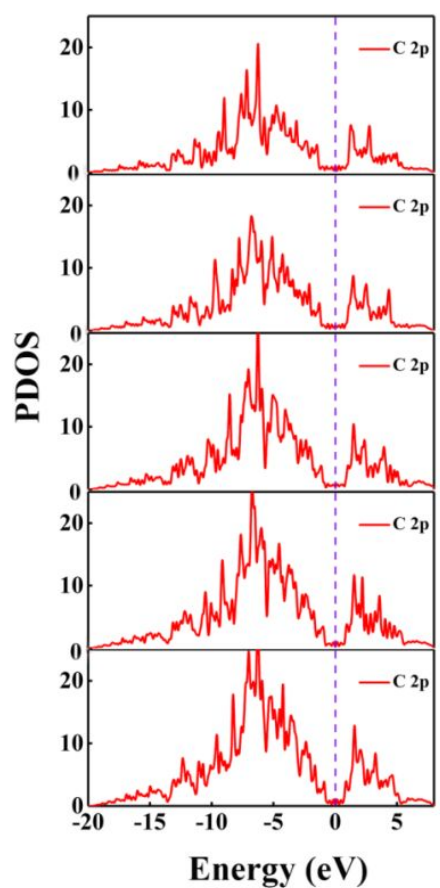

(a)

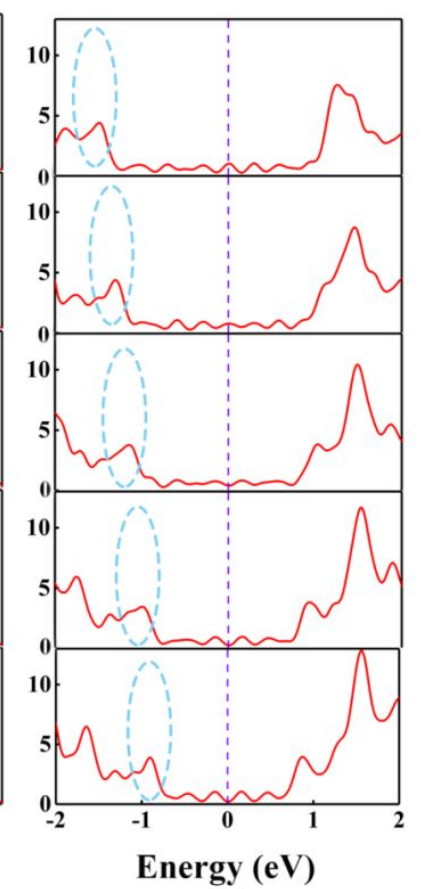

(b)

Figure S3. PDOS for CNT $(n, n)(n=5-9)$. C-state is represented by red curves. The violet dotted line represents the Fermi energy, which is assigned a value of zero.

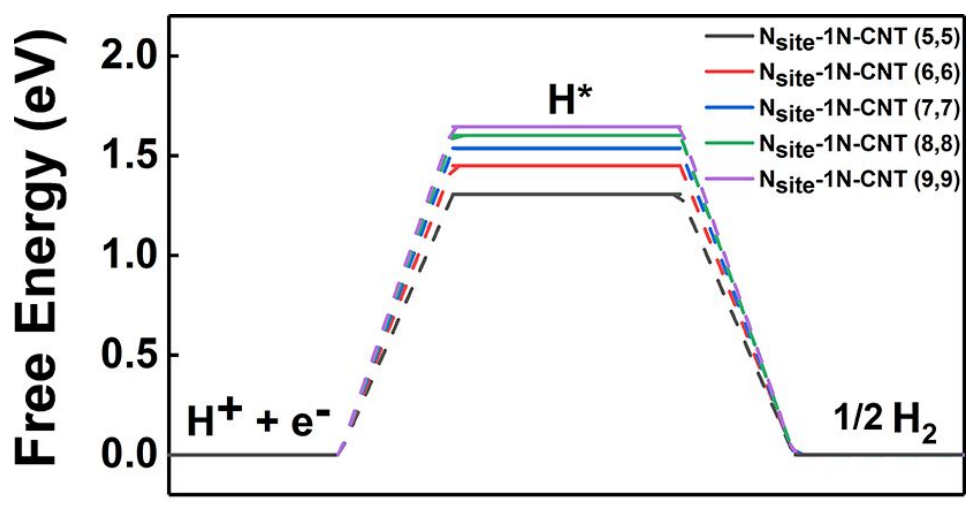

Reaction Coordinate

Figure S4. The Calculated $\Delta G_{\mathrm{H}^{*}}$ of $\mathrm{N}_{\text {site }}-1 \mathrm{~N}-\mathrm{CNT}(n, n)(n=5-9)$. 